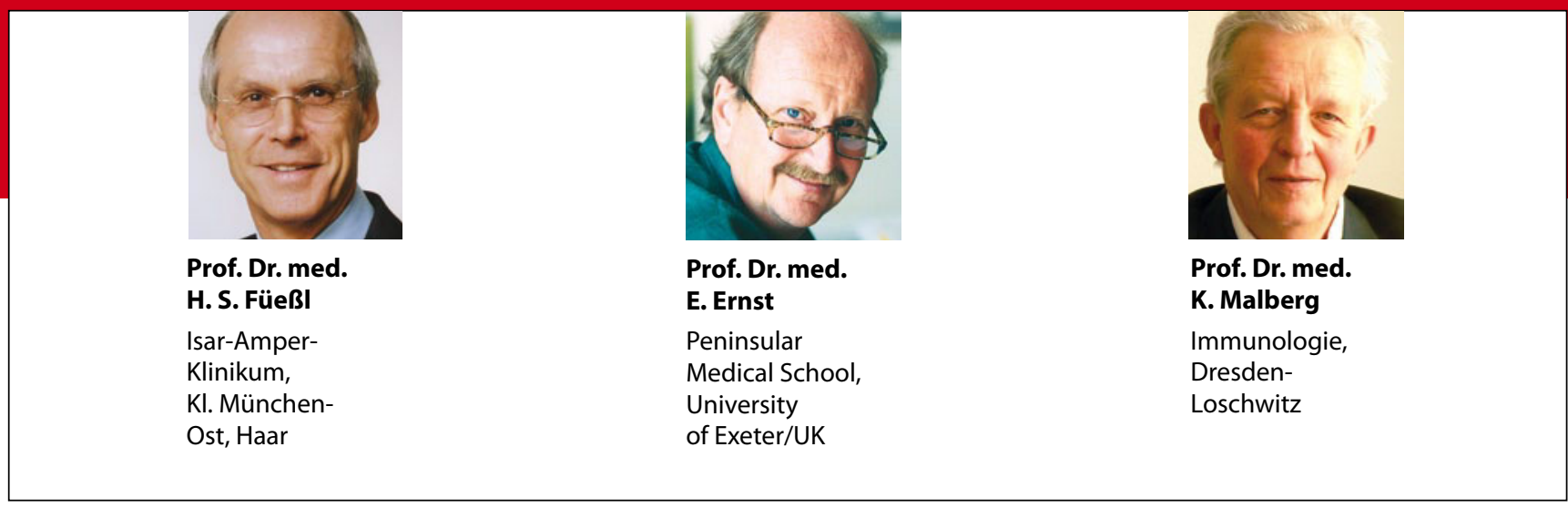

\title{
Hohe Gesundheitskosten sind keine Garantie für ein langes Leben
}

\section{Die Lebenserwartung der Menschen in den hochentwickelten Ländern steigt nach wie vor stetig an. Selbst die zunehmende Adipositas kann diesen Trend (noch) nicht brechen. Aber: Menschen in Ländern mit ho- hen Gesundheitskosten leben nicht unbedingt länger als Personen in Ländern mit niedrigeren Ausgaben.}

- Prof. David Leon von der London School of Hygiene and Tropical Medicine hat statistische Daten aus verschiedenen Ländern (Daten der WHO und die Human Mortality Database) unter die Lupe genommen. Der Hauptaugenmerk seiner Studie liegt auf Europa, aber auch die Daten aus Japan und den USA wurden mit einbezogen.

Die Lebenserwartung der Westeuropäer liegt bei durchschnittlich 78 Jahren, die Deutschen werden sogar im Mittel 80 Jahre alt. Damit nahm in Europa in den letzten 20 Jahren die Lebenserwartung um drei Jahre zu, obwohl sich die Zahl der Fettleibigen verdoppelte. Ein Stopp dieser Entwicklung zeichnet sich nicht ab, was möglicherweise mit einem Rückgang der Raucher und eine bessere medizinische Versorgung zu erklären ist.
Im Gegensatz zu den westlichen Industrienationen sind die Trends hinsichtlich der Lebenserwartung in Zentral- und Osteuropa sowie in Teilen der ehemaligen Sowjetunion unterschiedlich und insgesamt negativ. In der ehemaligen Sowjetunion nahm die Lebenserwartung in der Gorbatschow-Ära zu,

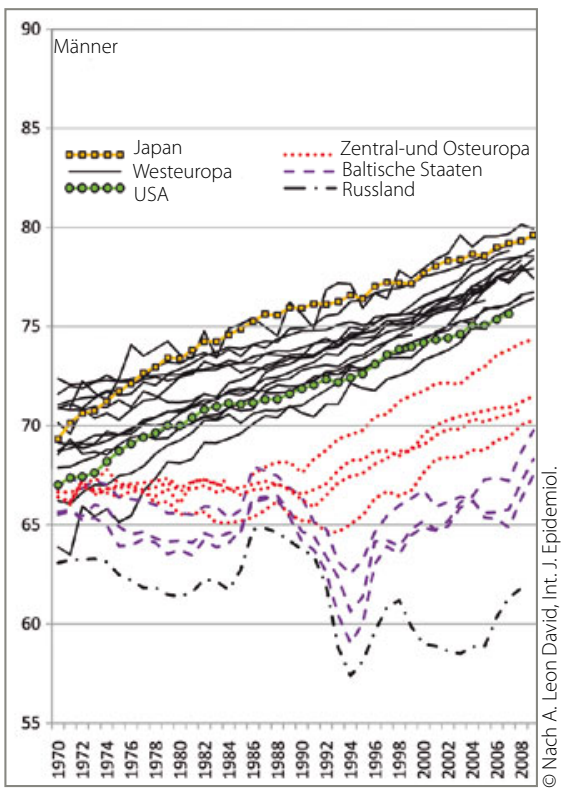

Voraussichtliche Lebenserwartung nach Geburtsjahr. fiel nach dem Zerfall der Sowjetunion steil ab und hat sich jetzt wieder etwas erholt. Der heutige Stand entspricht dem Stand vor etwa 40 Jahren. Die insgesamt schlechteren Werte in Osteuropa sollen auf den sehr hohen Alkoholkonsum in diesen Ländern zurückzuführen sein.

\section{Kommentar}

Aus einem höheren Bruttoinlandsprodukt - das ja auch höhere Ausgaben für Gesundheit gestattet - allein lassen sich die Unterschiede in den durchschnittlichen Lebenserwartungen nur bedingt erklären.

Die US-Amerikaner geben wohl weltweit am meisten Geld für Gesundheit aus. Dennoch rangieren die USA bei der Lebenserwartung nur dort, wo die westeuropäischen Schlusslichter zu finden sind. Großbritannien hingegen gehört trotz niedriger Ausgaben zu den Ländern mit der höchsten Lebenserwartung.

K. MALBERG .

\footnotetext{
- A. Leon David

(London School of Hygiene \& Tropical Medicine, Keppel Street, London WC1E 7HT, UK; E-mail: david.leon@lshtm.ac.uk) Trends in European life expectancy: a salutary view. Advance Access on March 17, 2011; Int. J. Epidemiol. 2011; doi:10.1093/ije/dyro61
} 